\title{
Reactive oxygen species in chick hair cells after gentamicin exposure in vitro
}

\author{
Keiko Hirose a , David M. Hockenbery ${ }^{\text {b }}$, Edwin W. Rubel ${ }^{\mathrm{a}, *}$ \\ "Virginia Merrill Bloedel Hearing Research Center, Department of Otolaryngology, Head and Neck Surgery, University of Washington, \\ Box 357923, Seattle, WA 98195, USA \\ b Fred Hutchinson Cancer Research Center, 1124 Columbia Street, Seattle, WA 98104, USA
}

Received 16 January 1996; revised 4 September 1996; accepted 14 September 1996

\begin{abstract}
Reactive oxygen species have been invoked as a causative agent of cell death in many different developmental and pathological states. The presence of free radicals and their importance in hair cell death due to aminoglycosides is suggested by a number of studies that have demonstrated a protective effect of antioxidants. By using dichlorofluorescin (DCFH) a fluorescent compound that is a reporter of reactive oxygen species, we have shown that free radicals are rapidly produced by avian hair cells in vitro after exposure to gentamicin. In addition, free radical scavengers, catalase and glutathione, were tested with DCFH fluorescent imaging for their ability to quench the production of reactive oxygen species in hair cells after drug exposure. Both free radical scavengers were very effective in suppressing drug-induced production of free radicals. Next, we investigated the ability of these antioxidants to preserve the structural integrity of hair cells after exposure to gentamicin. We were not able to detect any attenuation of the hair cell loss using antioxidants in conjunction with gentamicin. This result must be qualified by the fact that the antioxidants used were not effective over long-term gentamicin exposure. Therefore, methodological constraints prevented adequately testing possible protective effects of free radical scavengers in this model system.
\end{abstract}

Keywords: Aminoglycoside; Ototoxicity; Reactive oxygen species

\section{Introduction}

Aminoglycoside antibiotics are a mainstay of medical therapy and have remained such despite their highly toxic side effects, ototoxicity and nephrotoxicity, because they are effective and inexpensive. Renal function is usually closely monitored in the inpatient setting, but changes in hearing thresholds are frequently not detected during a patient's hospital course. Therefore, understanding the mechanism of aminoglycoside ototoxicity might assist in the prevention of hearing loss among these patients and also in elucidating those pathways involved in hair cell death.

\footnotetext{
* Corresponding author. Tel.: +1 (206) 543.8360 ; fax: +1 (206) 616 1828; e-mail: rubel@u.washington.edu
}

The avian cochlea, basilar papilla, lends itself to a great number of experimental approaches to the problem of ototoxicity, in part because it is readily surgically accessible, the dissection is technically straightforward, and organ and tissue culture preparations from mature tissue have been developed (Oesterle et al., 1993; Stone et al., 1995, 1996). Richardson and colleagues pioneered the use of cochlear explants from neonatal mouse inner ear to demonstrate morphological changes in mammalian hair cells after exposure to aminoglycosides using a similar culture technique (Richardson and Russell, 1991; Kotecha and Richardson, 1994). While the structure of the chick basilar papilla is somewhat different from that of the mammalian cochlea, it has been well established that the avian auditory system is analogous to the mammalian auditory system with regard to its response to noise and to drugs such as aminoglycosides. The culture techniques that have 
been developed for mature chick inner ear sensory epithelium also greatly facilitate its use in fluorescent imaging such as in the methods described here.

Research that has been dedicated to understanding the mechanism of aminoglycoside ototoxicity (Henley and Rybak, 1993; Schacht, 1993; Hutchin and Cortopassi, 1994; Matz, 1993) has suggested the possibility of free radical involvement (Pierson and Møller, 1981; Bock et al., 1983; Hoffman et al., 1987, 1988; Garetz et al., 1994a,b). The majority of these inquiries have documented a protective effect of antioxidants in aminoglycoside-induced hearing loss. However, none of these experiments has actually attempted to detect the formation of free radicals in hair cells exposed to these ototoxic antibiotics. There has been recent evidence of in vitro production of free radicals with gentamicin when combined with iron (Priuska and Schacht, 1995). In cultured renal cortical cells, free radical production due to gentamicin was measured using flow cytometry and dichlorofluorescin diacetate as a fluorescent marker of hydrogen peroxide activity (Swann and Acosta, 1990). Using this technique, these investigators found that gentamicin did not significantly increase the activity of hydrogen peroxide in renal cells. Using a similar technique, we have investigated whether free radicals are produced in hair cells exposed to gentamicin. In addition, we investigated whether antioxidants can effectively inhibit gentamicin-induced hair cell loss in in vitro preparations of chick basilar papilla.

The term 'free radical' refers to any generic type of atom, ion, or molecule with an unpaired electron, such as iron, which is not necessarily derived from oxygen. The term 'free radical' will be used in this paper interchangeably with 'reactive oxygen species' although 'reactive oxygen species' is the more precise term. We have used a compound, dichlorofluorescin diacetate (DCFH diacetate), which has been used in the past, primarily with flow cytometry (Nasr-Esfahahi et al., 1990; Heck et al., 1992; Saito et al., 1992; Suzuki et al., 1993; Reynolds and Hastings, 1995). This compound is an ester which is cell permeable and is deesterified by intracellular esterase to produce dichlorofluorescin, DCFH, a non-cell permeable moiety. DCFH will convert into its fluorescent form, dichlorofluorescein (DCF), only after oxidation by hydrogen peroxide. Thus, free radical formation can be assessed by measuring fluorescent activity of DCFH. We have applied the use of this compound to detect the presence of free radicals in hair cells in vitro, before and after gentamicin exposure. After establishing the effects of gentamicin first, on free radical production and second, on hair cell loss, we attempted to examine if there was a direct causal relationship between these two responses to gentamicin treatment. Hair cell survival was examined in explants exposed to gentamicin or gentamicin in the presence of free radical scavengers.

\section{Materials and methods}

\subsection{Hair cell culture}

In order to prepare each set of cultures of the auditory sensory epithelium, twelve white Leghorn chickens (Gallus domesticus, H and N International, Redmond, WA) 7-12 days post-hatch were decapitated, the tympanic membrane was removed, and the basilar papilla (avian cochlea) was rapidly dissected under sterile conditions (Stone et al., 1995). The entire papilla was immediately placed in sterile Eagle's modified essential medium (E-MEM, Gibco) supplemented with $0.1 \%$ bovine serum albumin (Sigma). The tegmentum vasculosum was sharply dissected off the organ, and the papilla was then placed in a $0.01 \%$ collagenase solution (Sigma) in E-MEM. The tectorial membrane was then removed from the surface of the sensory epithelium, and the hair cells and supporting cells were harvested in monolayer sheets. Hair cells and supporting cells located on the basal end of the papilla were separated from those located on the apical end, and these two cell populations were plated separately. We refer to these as sensory epithelium (SE) cultures, because they contain exclusively hair cells and supporting cells of the SE (Stone et al., 1996). All animal procedures were approved by University of Washington Animal Care Committee.

SE cultures were grown on 8-well chambered coverslips for imaging or 16-well chambered slides for cell density counting (Nunc Inc., Naperville, IL). SE culture medium was made with Dulbecco's modified essential medium with F12 supplement (D-MEM-F12, Gibco), $5 \%$ fetal bovine serum (Sigma), $0.5 \%$ glucose and hormone supplement, consisting of $100 \mu \mathrm{g} / \mathrm{ml}$ transferrin, $25 \mu \mathrm{g} / \mathrm{ml}$ insulin, $60 \mu \mathrm{M}$ putrescine, $30 \mathrm{nM}$ selenium, and $30 \mathrm{nM}$ progesterone (all supplied by Sigma). SE cultures were incubated at $37^{\circ} \mathrm{C}$ for $48 \mathrm{~h}$ prior to use for imaging and prior to gentamicin exposure for cell density counting. This culturing procedure was repeated 16-20 times for each treatment group for both imaging and cell counting.

\subsection{DCFH imaging}

Prior to using SE cultures in imaging experiments, cultured fibroblasts were used to determine the optimal DCFH loading concentration and duration. 3T3 cultured fibroblasts (American Type Culture Collection, Rockville, MD) were loaded with $5 \mu \mathrm{M}, 10 \mu \mathrm{M}$, $20 \mu \mathrm{M}$ or $40 \mu \mathrm{M}$ dichlorofluorescin diacetate (DCFDA, Molecular Probes, Eugene, OR) in sterile D-MEM/ $\mathrm{F} 12$ for 10,15 , or $20 \mathrm{~min}$ at $37^{\circ} \mathrm{C}$ in the dark. The cells were then rinsed with fresh D-MEM, and the cultures were imaged on a Nikon Diaphot inverted microscope over a $5 \mathrm{~min}$ interval with images acquired every $10 \mathrm{~s}$. A standard FITC filter cube was used with an excitation 
wavelength of $488 \mathrm{~nm}$ and emission wavelength of 512 $\mathrm{nm}$. The aim of these preliminary experiments was to determine what loading concentration would minimize the non-specific increase in fluorescence caused by photoexcitation in the control setting. Another set of fibroblasts were used in which DCFH was loaded at the same concentrations and for the same durations, but $3 \mathrm{mM}$ hydrogen peroxide was added after acquisition of the first image. Here we sought to ensure that the loading concentration and time were sufficient to cause a significant increase in fluorescent intensity after direct stimulation with peroxide. $20 \mu \mathrm{M} \mathrm{DCFH}$ and $15 \mathrm{~min}$ were chosen as the optimal loading time and concentration based on a minimum detectable increase in fluorescence in the negative control and maximum increase in fluorescence in the positive control.

In addition, preliminary experiments were undertaken using different neutral density filters and different objectives, again, to optimize the resolution between positive and negative controls. We found that using an objective greater than $25 \times$ yielded an unacceptable degree of photoexcitation in the fibroblast controls. This non-specific increase in DCFH fluorescent intensity was due to light exposure alone at the higher magnifications. Use of the $25 \times$ or lower power objective minimized this photoexcitation artifact. The $10 \%$ neutral density filter was optimal in reducing the effects of photoexcitation and allowing maximum discrimination between negative and positive controls using $3 \mathrm{mM}$ hydrogen peroxide treatment of the fibroblasts.

Subsequent experiments using SE cultures were performed according to the guidelines established by these preliminary findings with fibroblasts. SE cultures were loaded with $20 \mu \mathrm{M}$ dichlorofluorescin diacetate in $\mathrm{DMEM} / \mathrm{F} 12$ for $15 \mathrm{~min}$ at $37^{\circ} \mathrm{C}$ in the dark. The explants were rinsed with DMEM/F12 and viewed using a Nikon Diaphot inverted microscope with a $25 \times$ objective. The standard FITC filter-cube was again used. Excitation wavelengths were attenuated to $10 \%$ of their original intensity by use of a neutral density filter. Hair cells in the SE cultures were initially visualized and focused under phase contrast, and then the first fluorescent image was acquired prior to drug exposure. Fluorescence analog images were acquired via an intensified CCD camera and stored as digital images using Image-1 software (Universal Imaging Corp., West Chester, PA). Cultures were then exposed to 100, 500, or $1000 \mu \mathrm{M}$ gentamicin (Elkins-Sinn, Cherry Hill, NJ) in DMEM-F12 immediately after acquisition of the first image, and images were acquired every $10 \mathrm{~s}$ thereafter. In those experiments conducted with a free radical scavenger, either $10 \mathrm{mM}$ glutathione or $1000 \mathrm{U} / \mathrm{ml}$ catalase (Boehringer Mannheim) was combined with $500 \mu \mathrm{M}$ gentamicin and applied to the culture well at the time of imaging. At the end of each experiment, $3 \mathrm{mM}$ hydrogen peroxide was added to the culture medium to confirm adequate loading of DCFH. In each case, maximum fluorescent intensity of DCFH was reached after direct stimulation with hydrogen peroxide. Controls were obtained using DMEM/F12 without gentamicin and with each of the free radical scavengers alone without gentamicin. Hydrogen peroxide $(3 \mathrm{mM})$ was also used at the conclusion of the control experiments to confirm activity and adequate loading of hair cells with DCFH. After each experiment was completed, fluorescent intensities were measured and analyzed from the stored digital image sequences using NIH image software.

\subsection{Hair cell density measurements}

Auditory SE cultures were grown as described above for $48 \mathrm{~h}$. They were then exposed to 100,500 , or 1000 $\mu \mathrm{M}$ gentamicin for $1 \mathrm{~h}$. Following gentamicin exposure, the cultures were washed with fresh culture medium 3 times and then returned to the incubator. In the experiments conducted with an antioxidant, hair cells were exposed to either $10 \mathrm{mM}$ glutathione or $1000 \mathrm{U} /$ $\mathrm{ml}$ catalase with $500 \mu \mathrm{M}$ gentamicin for $1 \mathrm{~h}$. Controls were obtained using culture medium without gentamicin and with medium supplemented with each of the free radical scavengers, also without gentamicin. After the cultures were exposed to the experimental treatment for $1 \mathrm{~h}$ and washed, they were allowed to survive in culture for an additional $6 \mathrm{~h}$ and then fixed in $4 \%$ paraformaldehyde. The $6 \mathrm{~h}$ incubation after drug exposure
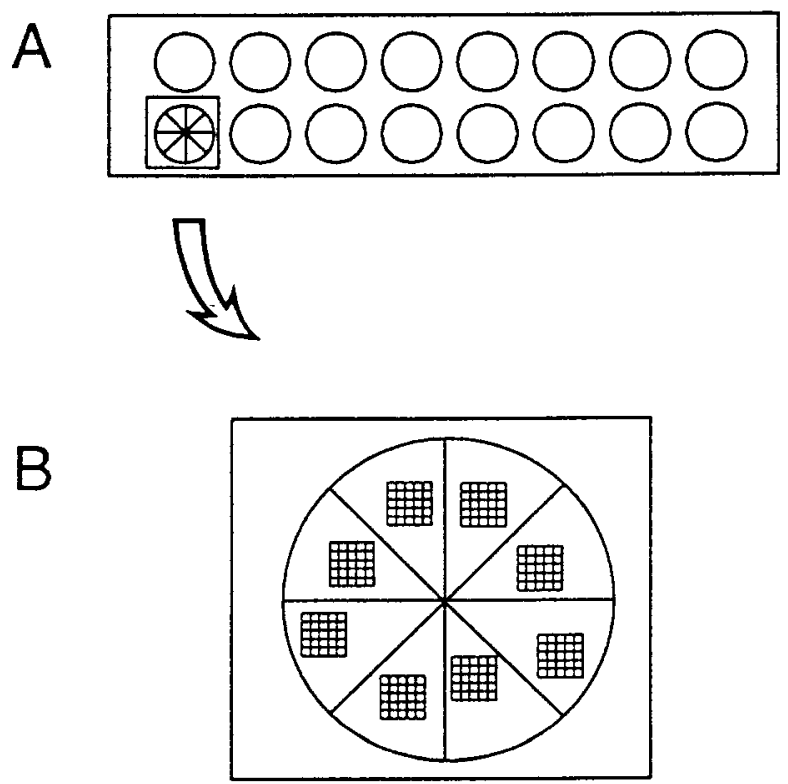

Fig. 1. Diagram of culture slide and method for measurements of hair cell density. A: Culture slide measuring $2.5 \times 8.5 \mathrm{~cm}$ with 16 round culture wells. B: Higher detail of one culture well, divided into eight sectors, showing reticule superimposed within each sector. Hair cells inside the reticule were counted for each sector and an average cell density was calculated for each culture well. 


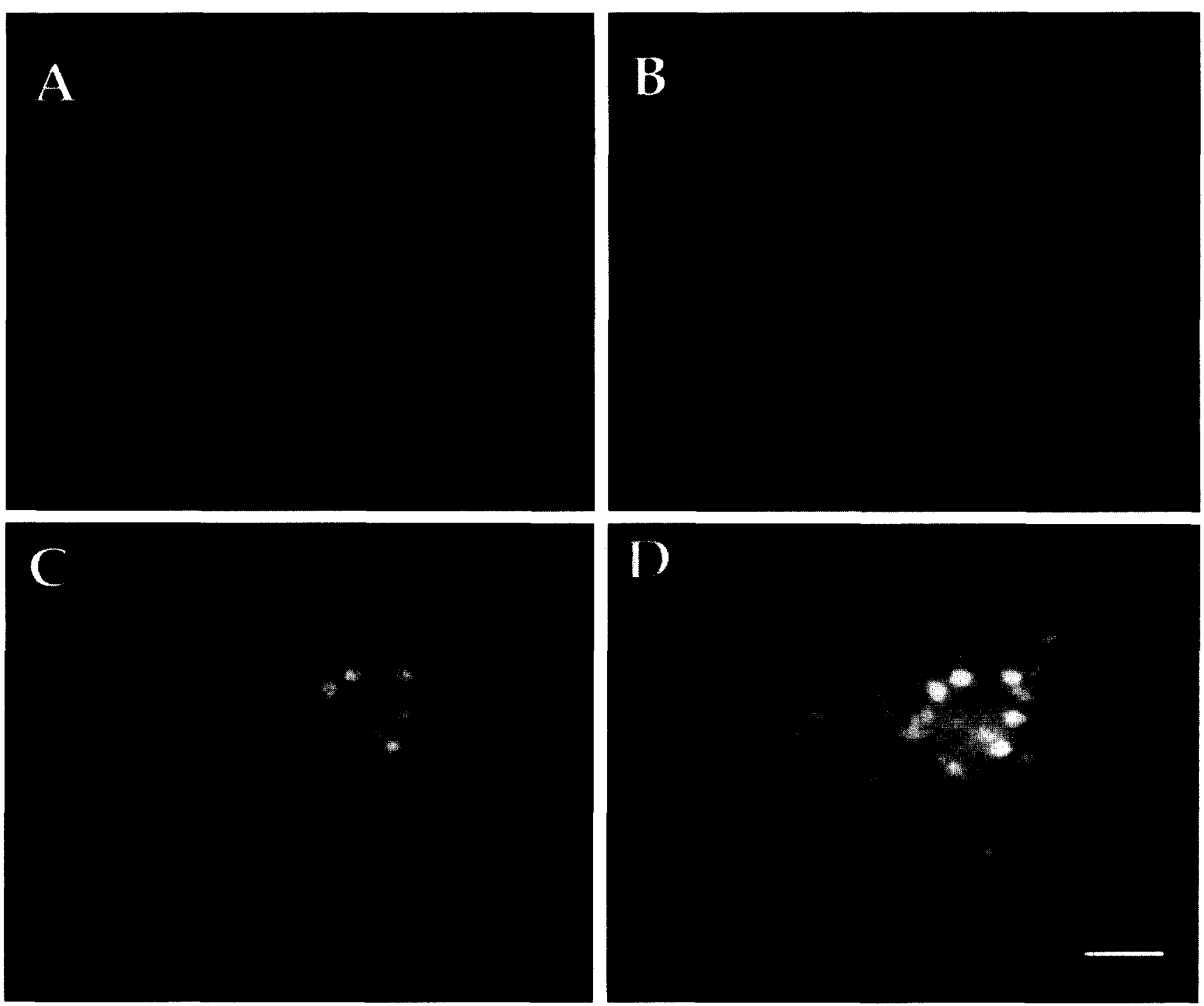

Fig. 2. Epifluorescence photomicrographs of representative live hair cell explants during DCFH imaging. A: Hair cell explant at initiation of imaging prior to $500 \mu \mathrm{m}$ gentamicin exposure. B: The same explant $50 \mathrm{~s}$ after gentamicin exposure. C: After $150 \mathrm{~s}$ of drug exposure. D: After addition of $3 \mathrm{mM}$ hydrogen peroxide (positive control). Note the gradual increase in fluorescent intensity over time after drug exposure and the rapid increase in fluorescent intensity after peroxide exposure. Calibration: $40 \mu \mathrm{m}$.

was included to allow time for hair cell stereocilia (presumably also the hair cells) to be lost from the explant due to the drug damage, thus enabling us to quantify the results of the treatment on hair cell survival. After 15 min fixation, the explants were stained with a $1: 50$ dilution of rhodamine phalloidin, a fluorescent marker of f-actin (Molecular Probes), in $0.1 \%$ Triton X-100 (Sigma) for $90 \mathrm{~min}$. The cell cultures were then rinsed in phosphate buffered saline 3 times, the removable culture chamber was detached, and the culture slides were coverslipped. Hair cells were viewed on a Leitz Orthoplan microscope using epifluorescence under a $25 \times$ objective.

To quantify the density of hair cells surviving in each condition, we used the following methods illustrated in
Fig. 1. Each culture slide contained 16 wells (Fig. 1A). Each round culture well was divided into eight equal sectors (Fig. 1B), and a $10 \times 10$ reticule was randomly placed onto each sector assuring that the reticule covered a region that contained adherent, well-stained cells. Each culture well measured $7 \mathrm{~mm}$ in diameter, and the reticule measured $0.5 \mathrm{~mm}$ across under $25 \times$ magnification. The number of hair cells that lay in the area of the reticule was counted for each of the eight sectors of the culture well. For those sectors bearing no attached supporting cells, no counts were registered. The number of phalloidin stained hair cells per square millimeter was averaged over all eight sectors for each explant. Hair cell density is reported as number of cells with intact stereocilia bundles per square millimeter of tissue area. 
10 seconds

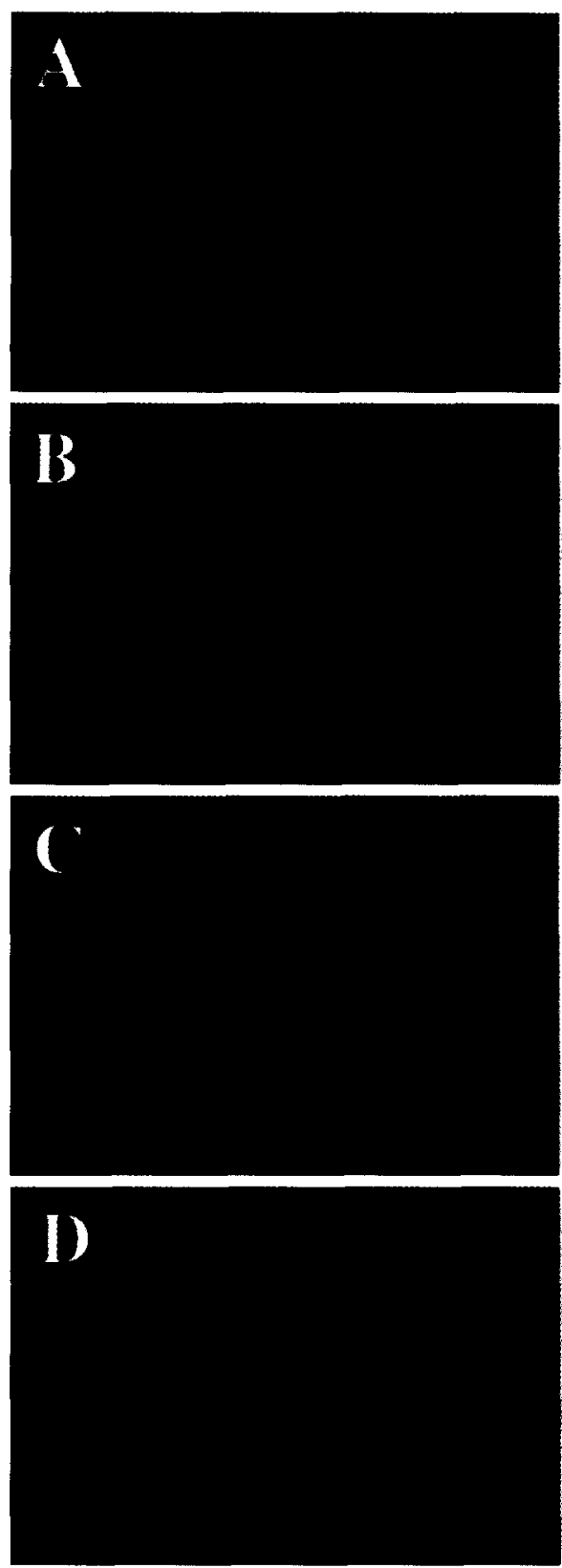

50 seconds
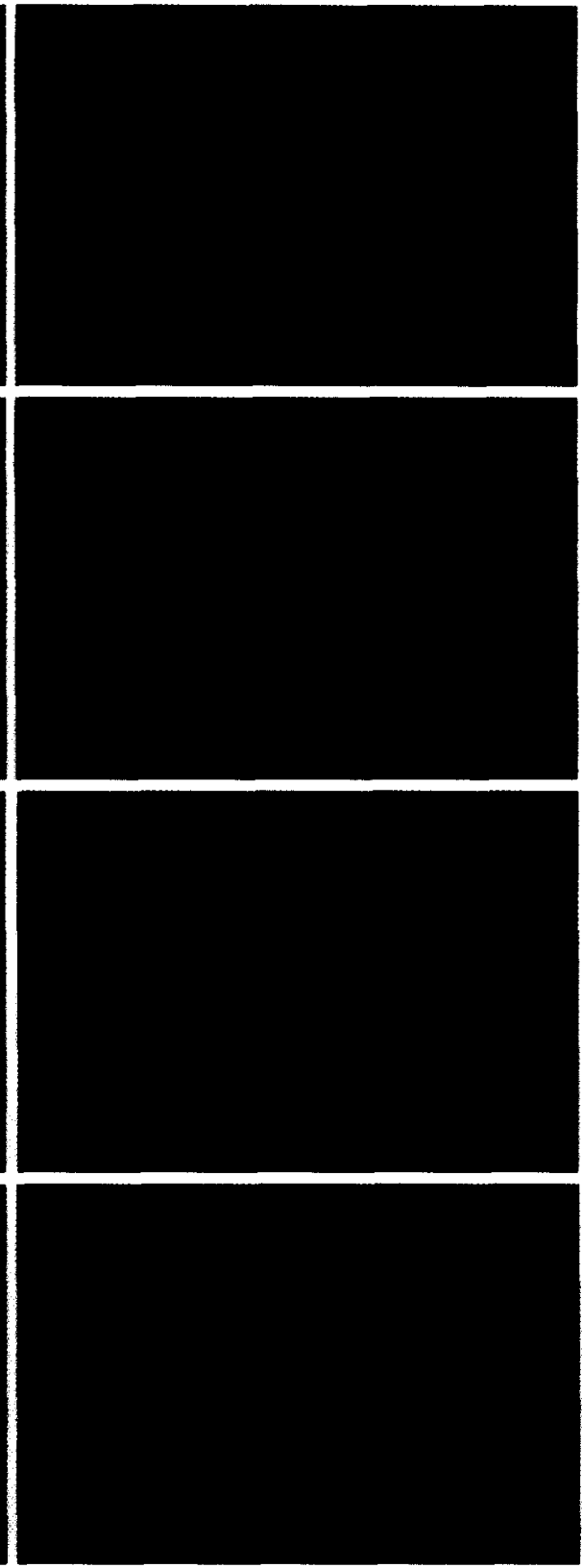

\section{0 seconds}
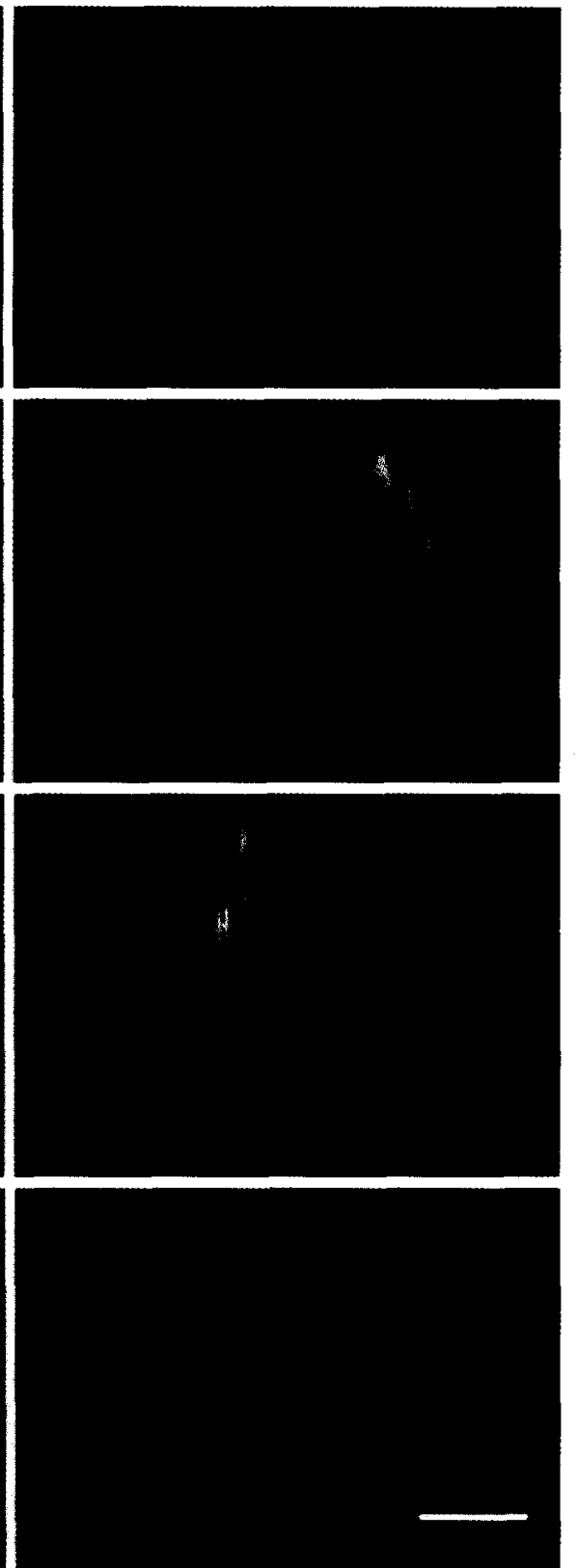

Fig. 3. Pseudocolor images of four live sensory epithelium explants at three time points after drug exposure. The pseudocolor scale represents fluorescent intensity where purple equals a low level of fluorescence and red equals a very high level of fluorescence. A 2-D hair cell explant is transformed into a 3-D image by using the level of fluorescent intensity as the $z$-axis. Therefore, the height of each peak represents the level of fluorescent intensity of one hair cell. A: Control explant imaged at 10,50, and $150 \mathrm{~s}$ after gentamicin exposure. B: Explant exposed to $500 \mu \mathrm{M}$ gentamicin at the same time points. C: Explant exposed to $1000 \mu \mathrm{M}$ gentamicin. Note the increasing levels of fluorescent intensity over time and with increasing gentamicin concentration. D: Explant exposed to $500 \mu \mathrm{M}$ gentamicin and $10 \mathrm{mM}$ glutathione. Here, the suppression of free radical production with the use of antioxidant is demonstrated. Calibration: $60 \mu \mathrm{m}$.

\section{Results}

\subsection{General observations}

Using the optimum parameters that had been established by the preliminary experiments using fibroblasts, hair cells did demonstrate a significant change in fluo- rescent activity after gentamicin exposure. Fig. 2 demonstrates responses from a representative explant from chick auditory epithelium during an imaging experiment conducted with $500 \mu \mathrm{M}$ gentamicin. Upon initiation of the experiment, there is a low level of fluorescence as shown in Fig. 2A. After addition of $500 \mu \mathrm{M}$ gentamicin to the culture medium, we consistently saw 


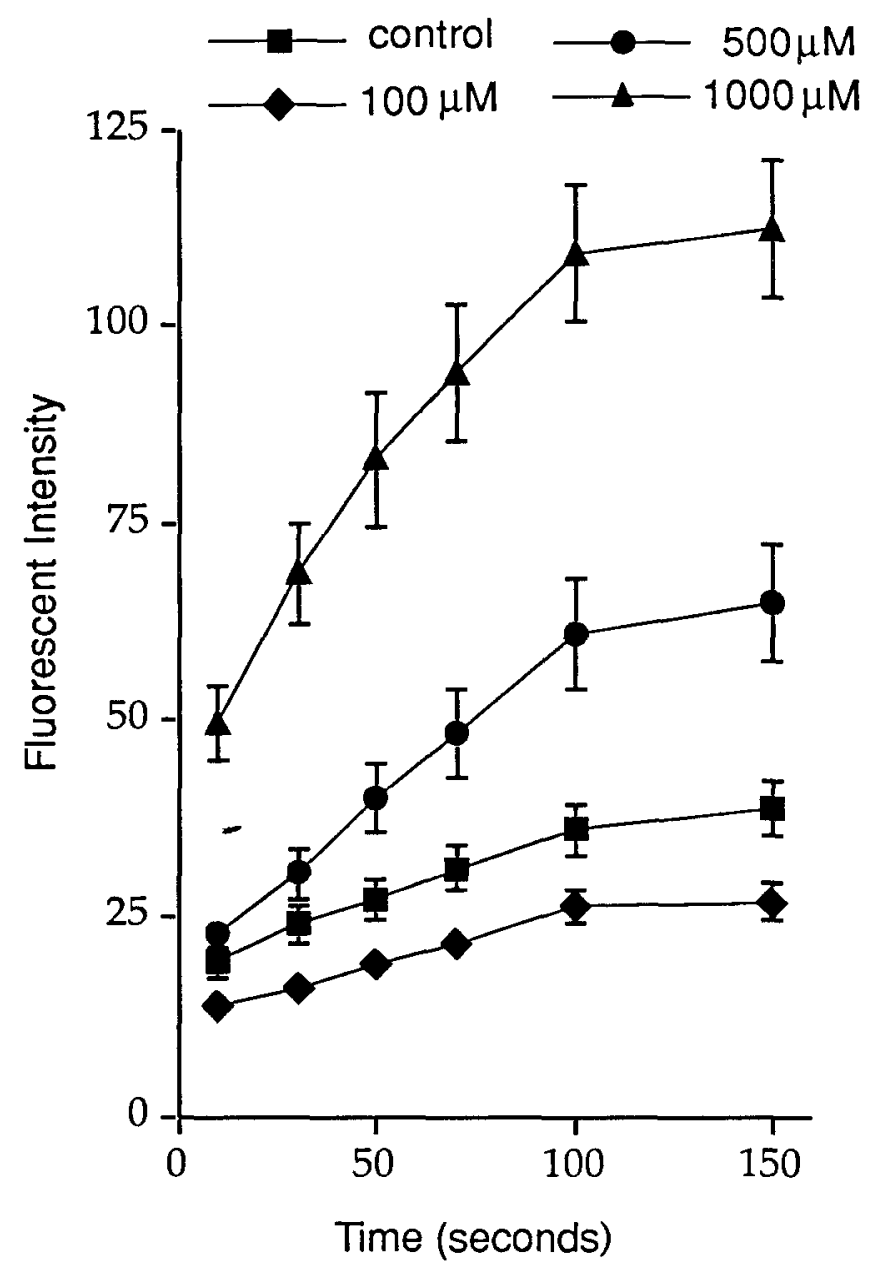

Fig. 4. Free radical production in hair cells after exposure to three concentrations of gentamicin. Hair cells explants were imaged after addition of $100 \mu \mathrm{M}$ gentamicin $(\bullet, n=21$ explants), $500 \mu \mathrm{M}$ gentamicin $(\bullet, n=16$ explants), and $1000 \mu \mathrm{M}$ gentamicin $(\wedge, n=17$ explants). $\mathbf{\square}$, controls $(n=16$ explants). Note the increase in free radical production with time and with dose of gentamicin. Control, 500 , and $1000 \mu \mathrm{M}$ gentamicin were found to be significantly different $(P<0.001)$. Control and $100 \mu \mathrm{M}$ gentamicin were not significantly different. Error bars: SEM. Where no error bars are shown, the SEM was smaller than the size of the symbol.

a increase in fluorescence of DCFH-labeled hair cells. Fluorescent images seen at $50 \mathrm{~s}$ and $150 \mathrm{~s}$ after exposure are shown in Fig. 2B,C. Finally, we added hydrogen peroxide to the medium after $3 \mathrm{~min}$ of drug exposure to demonstrate that DCFH fluorescent intensity had not been saturated, and indeed, there was an even further increase in fluorescent intensity (Fig. 2D).

\subsection{Free radical production with various concentrations of gentamicin}

Fig. 3 demonstrates four representative SE cultures $(\mathrm{A}, \mathrm{B}, \mathrm{C}$, and $\mathrm{D})$ imaged at 10,50 , and $150 \mathrm{~s}$ after drug exposure, represented by the three columns. These explants are depicted in pseudocolor where red represents a very high level of fluorescence and purple represents a low level of fluorescence. Two-dimensional data, as seen in Fig. 2, were transformed into a 3-D image by projecting the level of fluorescent intensity onto the $z$ axis of the image. Thus, the peaks in Fig. 3 represent indi- vidual hair cells with high levels of fluorescent activity as depicted by their color on the pseudocolor scale, as well as the $z$-coordinate, the height of each peak. Control explants, shown in Fig. 3A, demonstrated a small increase in fluorescent intensity over the three time points. Fig. 3B,C show explants exposed to 500 and $1000 \mu \mathrm{M}$ gentamicin, respectively. As this figure demonstrates, there is an increase in the maximum level of fluorescent intensity reached with the higher gentamicin concentration, and there is also a greater number of hair cells that obtain a high level of fluorescence with the higher drug concentration. When hydrogen peroxide was added to these cultures at the conclusion of the experiment, even higher fluorescent intensities were reached, confirming adequate DCFH loading and confirming that DCFH fluorescence had not been saturated (images not shown).

These imaging experiments were repeated and the data compiled for the controls and for each of the three gentamicin concentrations. In each explant, 20 cells 


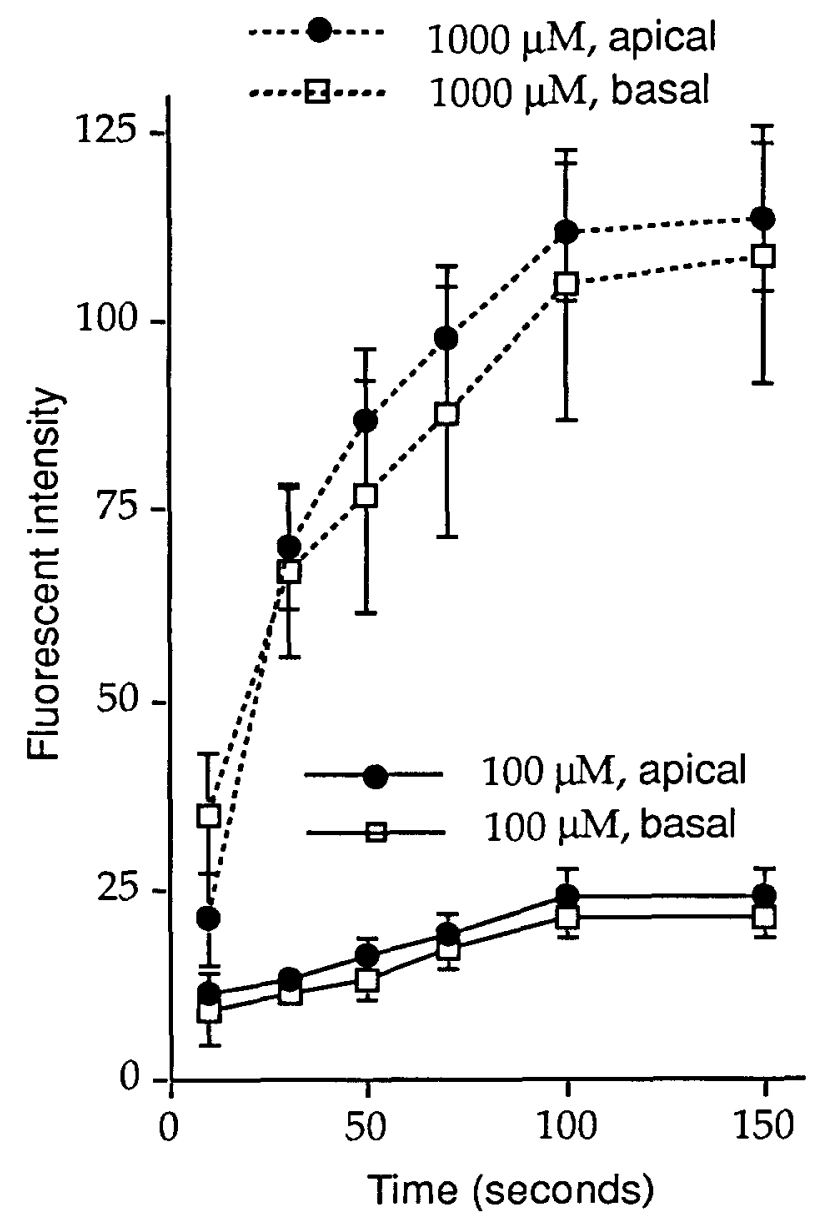

Fig. 5. Free radical production in apical versus basal hair cells. $\square$, basal hair cells ( $n=9$ explants for each concentration); 0 , apical hair cells ( $n=16$ explants for each concentration). There was no significant difference between the free radical production in apical versus basal hair cells in either of the two different gentamicin concentrations tested. Error bars: SEM. Where no error bars are shown, the SEM was smaller than the size of the symbol.

were randomly selected, and fluorescent intensities for each of the 20 cells were measured for each time point. The values of the 20 cells were averaged for each explant at each time point. The grand mean for each time point was generated by averaging the means from $16-$ 20 explants for each time point. Standard errors were calculated from the means for the individual explants. These calculations were then repeated for each gentamicin concentration. Fig. 4 demonstrates both the timeand dose-dependence of the free radical production due to gentamicin exposure. A steep rise in oxygen free radical formation was detected during the initial minute after exposure to gentamicin in the 500 and $1000 \mu \mathrm{M}$ groups, but not in the control group or the $100 \mu \mathrm{M}$ exposure group. Note that the level of fluorescent intensity plateaued after $120 \mathrm{~s}$ of exposure to gentamicin.

These data were analyzed by a 2-way analysis of variance (ANOVA) which showed significant effects of drug concentration $(P<0.001)$ and of time $(P<0.001)$ on fluorescent intensity. Notably, there was also a significant time by concentration interaction $(P<0.001)$. In other words, fluorescent intensity increased significantly over time, and the slope of the increase in fluorescent intensity increased as a function of gentamicin concentration. Multiple comparison with the StudentNeuman-Keuls test of the data from different concentrations averaged over time revealed significant differences between all groups $(P<0.001)$ except in the comparison of the control group versus the $100 \mu \mathrm{M}$ gentamicin group. While the mean fluorescent intensities of the $100 \mu \mathrm{M}$ gentamicin group were lower than those of the control, this difference was not statistically significant.

Free radical formation in apical and basal hair cells was directly compared in 48 explants. Fig. 5 shows the results of these experiments for two concentrations of gentamicin. This figure indicates that basal and apical hair cells did not differ with respect to their production

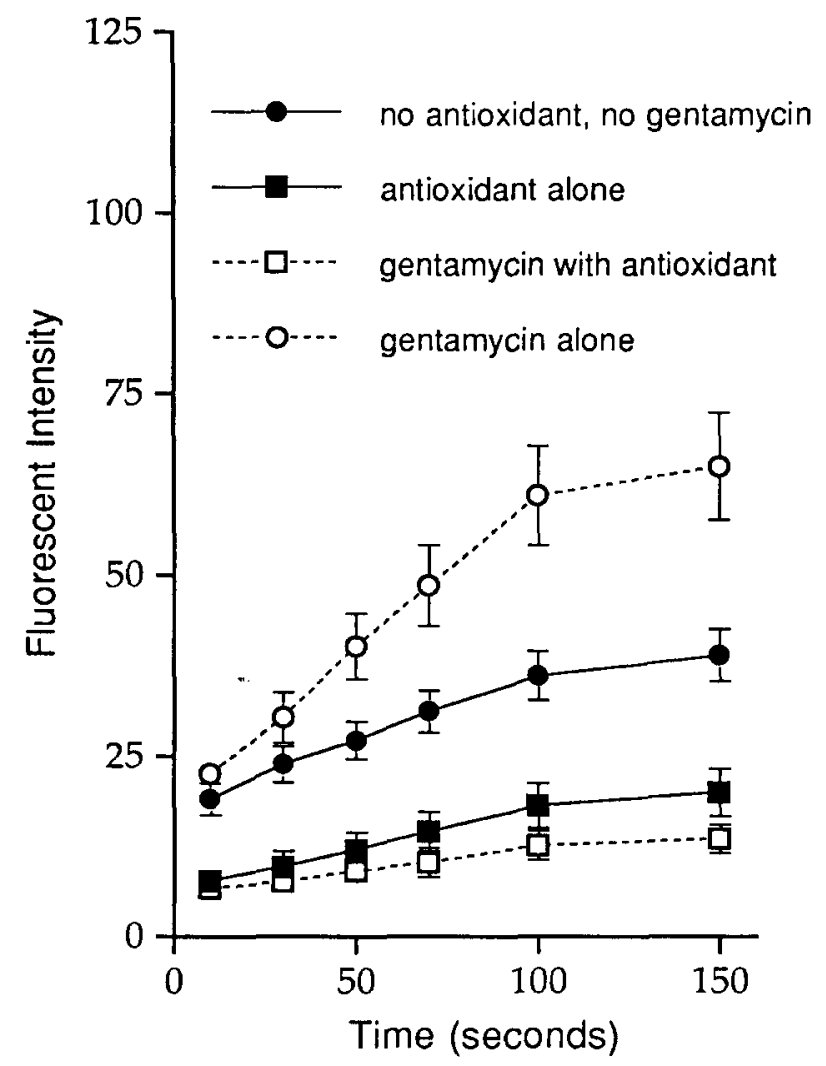

Fig. 6. Free radical production after exposure to antioxidant in conjunction with gentamicin. The controls $(\bullet, n=16$ explants) showed a higher level of fluorescent intensity than the explants treated with antioxidant alone ( $\square, n=16$ explants). Also, the explants treated with gentamicin alone $(0, n=16$ explants) showed a higher level of fluorescent intensity than those treated with gentamicin and antioxidant ( $\square, n=9$ explants). Antioxidants effectively suppressed the increase in free radicals produced by $500 \mu \mathrm{M}$ gentamicin $(P<0.001)$. Antioxidants also effectively suppressed free radicals produced in the control cultures $(P<0.001)$. Error bars: SEM. Where no error bars are shown, the SEM was smaller than the size of the symbol. 


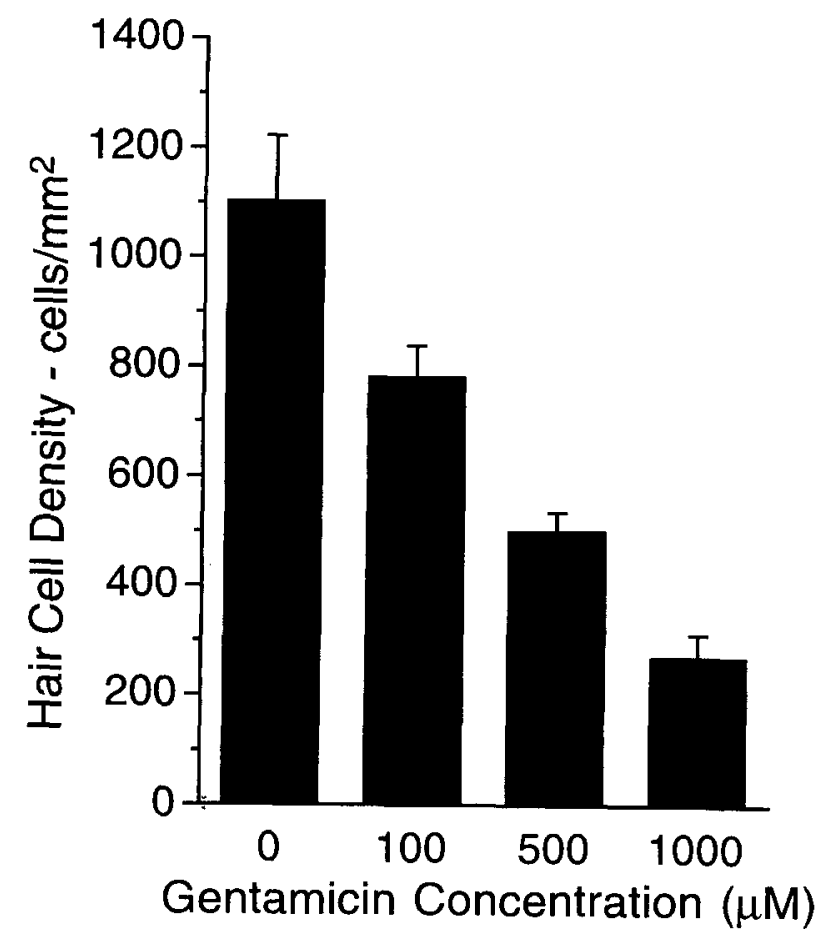

Fig. 7. Hair cell density after exposure to three concentrations of gentamicin. There is a systematic decrease in hair cell density with an increase in gentamicin concentration. $100 \mu \mathrm{M}$ gentamicin failed to cause a significant effect on hair cell density $(P=0.06)$, but cultures exposed for $1 \mathrm{~h}$ to 500 or $1000 \mu \mathrm{M}$ gentamicin had lower hair cell densities than controls $(P<0.001)$. In total, 69 culture wells were counted for this experiment. Error bars: SEM.

of reactive oxygen species in response to either 100 or $1000 \mu \mathrm{M}$ gentamicin treatment. A 2-way ANOVA failed to show a significant effect of frequency location (apical vs. basal) on fluorescent intensity of DCFH $(P=0.7)$. This lack of effect persisted in both concentrations of gentamicin.

\subsection{Free radical production with gentamicin and antioxidants}

Antioxidants, glutathione (14 explants) and catalase (11 explants), were tested for their ability to suppress the increase in free radicals in cultured hair cells after gentamicin exposure. One concentration of gentamicin, $500 \mu \mathrm{M}$, was chosen to examine this effect. Glutathione was chosen for its small size and its relative ability to permeate cell membranes and thus, suppress the formation of intracellular free radicals. Catalase, on the other hand, is a larger molecule and does not usually permeate the cell membrane and thereby acts primarily as a scavenger of free radicals from an extracellular source.

When hair cell explants were exposed to $500 \mu \mathrm{M}$ gentamicin accompanied by antioxidant, the burst of free radicals previously demonstrated with drug exposure was entirely quenched (Fig. 3D). Compared to the previous images, and even compared to the control ex- plant in Fig. 3A, those hair cells exposed to the drug in combination with an antioxidant failed to produce any significant increase in free radicals. When hydrogen peroxide was added at the conclusion of these experiments, there was a slight increase in fluorescent intensity, but not as large as the increase seen in those cultures without antioxidant (image not shown).

Fig. 6 demonstrates the mean fluorescent intensities in hair cells over time with and without gentamicin, and with and without antioxidant. The control values for fluorescent intensity are clearly less than those for the gentamicin treated group, and both groups treated with antioxidant have much lower fluorescent intensities than either the group treated with gentamicin alone or the control group. A 3-way ANOVA revealed a significant effect of antioxidant on fluorescent intensity $(P<0.001)$, a significant effect of time on fluorescent intensity $(P<0.001)$, and significant effect of gentamicin on fluorescent intensity $(P<0.001)$. Again, as in Fig. 4 , there was a significant time by treatment interaction, indicating that the effect of time on fluorescent intensity was altered by presence or absence of antioxidant $(P<0.001)$.

Two-tailed $t$-tests were performed on the fluorescent intensity of the different treatment groups, averaged over time. These tests revealed several findings. First, there was no significant difference between the effects of glutathione and catalase, the two antioxidants $(P=0.07)$. Therefore, the cultures treated with the two antioxidants were collapsed into one group. Two-tailed $t$-tests were then recalculated with the new treatment groups, and there was a highly significant decrease in the fluorescent intensity of the group treated with gentamicin and antioxidant as compared with the group treated with gentamicin alone $(P<0.001)$, demonstrating the effective quenching of free radicals with both glutathione and catalase. Furthermore, there was a significant decrease in fluorescent intensity in the antioxidant group as compared to controls $(P<0.001)$. From this evidence we conclude that there is a baseline level of free radical production in this culture setting, even in the control group, that can be reduced with the use of antioxidant.

\subsection{Hair cell density following gentamicin treatment}

Hair cell density was measured from cultures $(n=69)$ that were exposed to concentrations of gentamicin ranging from 0.1 to $1.0 \mathrm{mM}$. The results are displayed in Fig. 7. Hair cell density was determined by the number of hair cells with intact stereociliary bundles per square millimeter of tissue. Hair cell density was assessed $6 \mathrm{~h}$ after a $1 \mathrm{~h}$ exposure to 100,500 , or $1000 \mu \mathrm{M}$ gentamicin. As demonstrated in Fig. 7, there is a systematic decrease in hair cell density with increasing concentration of gentamicin. This experiment revealed that hair 

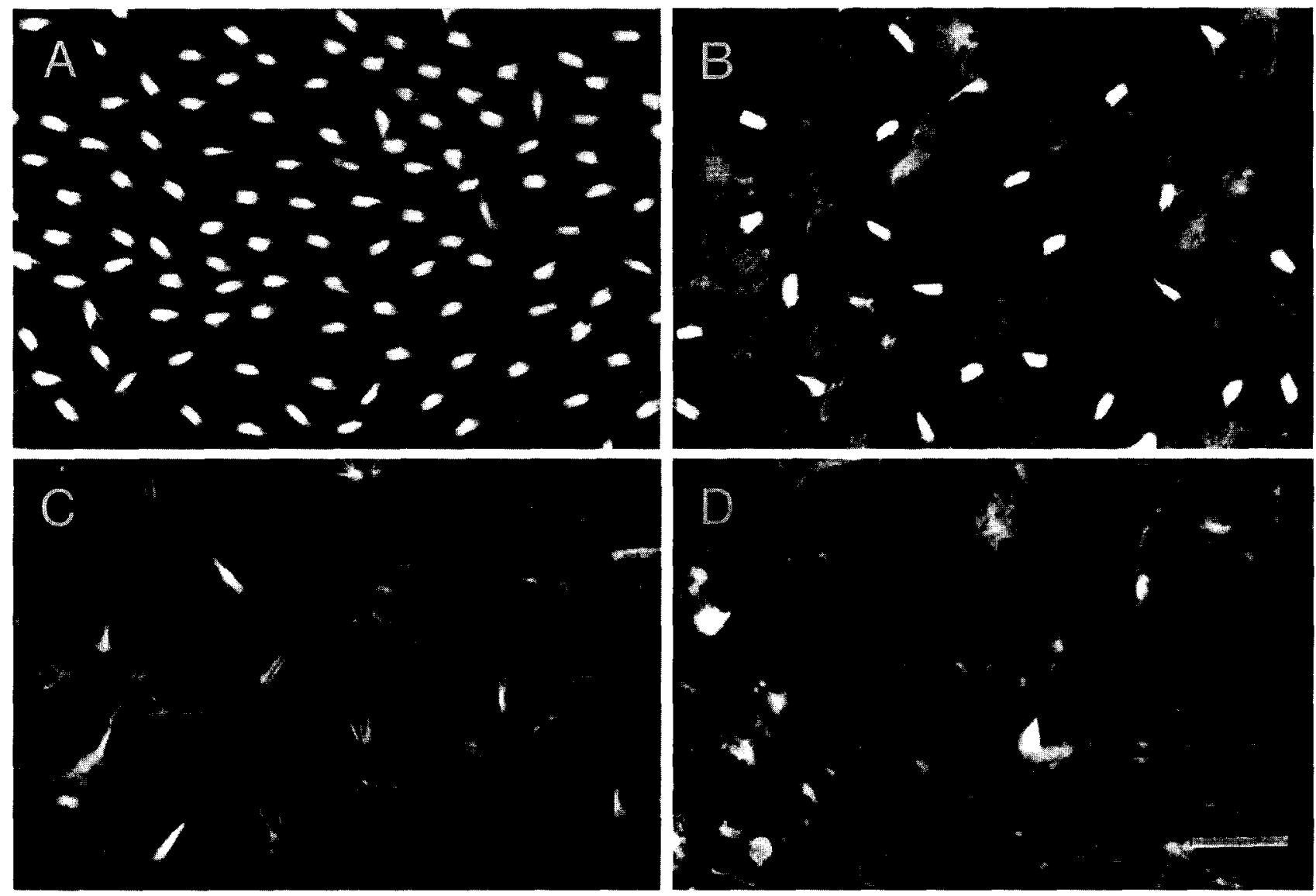

Fig. 8. Epifluorescent photomicrographs of hair cell cultures stained with rhodamine-phalloidin after exposure to gentamicin or gentamicin and antioxidant. A: Control explant with fairly normally spaced stereocilia bundles and tightly packed array of hair cells (cell density $=1101$ cells/ $\mathrm{mm}^{2}$ ). B: Explant after exposure to $10 \mathrm{mM}$ glutathione alone. Notice the significant loss of stereocilia bundles and expansion of the apical surfaces of hair cells (cell density $=744$ cells $/ \mathrm{mm}^{2}$ ). C: Explant treated with $1 \mathrm{~h}$ exposure to $500 \mu \mathrm{M}$ gentamicin $\left(\mathrm{cell}\right.$ density $=500 \mathrm{cells} / \mathrm{mm}^{2}$ ). D: Explant treated with $1 \mathrm{~h}$ exposure to $1000 \mu \mathrm{M}$ gentamicin (cell density $=269 \mathrm{cells} / \mathrm{mm}^{2}$ ). In the higher concentrations of gentamicin, hair cell loss was evident and fairly consistent. Calibration: $40 \mu \mathrm{m}$.

cell density in culture varied inversely with gentamicin concentration and was inversely proportional to the degree of fluorescent intensity produced by DCFH.

As in the experiments with DCFH, the explants were separated into apical and basal hair cell populations. A 1-way ANOVA on the apical cells showed a significant effect of drug concentration on hair cell density $(P<0.001)$. There was, however, only a marginally significant effect of gentamicin on cell density of basal hair cell explants $(P=0.05)$, largely because the cell density was extremely low in all concentrations, including controls (data not shown). This finding was not a result of insufficient tissue as there were abundant supporting cells in these cultures, but there were much fewer surviving basal hair cells, even in the control group. The basal hair cells were therefore eliminated from further analysis, and the data reported in the remaining cell density experiments reflect only the apical hair cell population.

Among the apical hair cell population, multiple comparisons revealed statistically significant differences in hair cell densities of the control, 500, and $1000 \mu \mathrm{M}$ gentamicin groups $(P<0.05)$. There was, however, no statistically significant difference between the control and $100 \mu \mathrm{M}$ gentamicin groups $(P>0.05)$. This pattern mirrors the findings of free radical production with these respective concentrations of gentamicin.

In summary, exposure to $100 \mu \mathrm{M}$ gentamicin was not sufficient to cause an increase in free radical production as compared with control media, nor was it sufficient to cause a significant decrease in hair cell density after $1 \mathrm{~h}$ exposure, as compared with control cultures. Starting at $500 \mu \mathrm{M}$ gentamicin, there was both an immediate increase in free radical production and an eventual decrease in hair cell density.

\subsection{Hair cell density with gentamicin and antioxidants}

We attempted to address the question of whether short-term suppression of reactive oxygen species, demonstrated in Fig. 6, would effectively save hair cells from gentamicin toxicity. To accomplish this, hair cell 


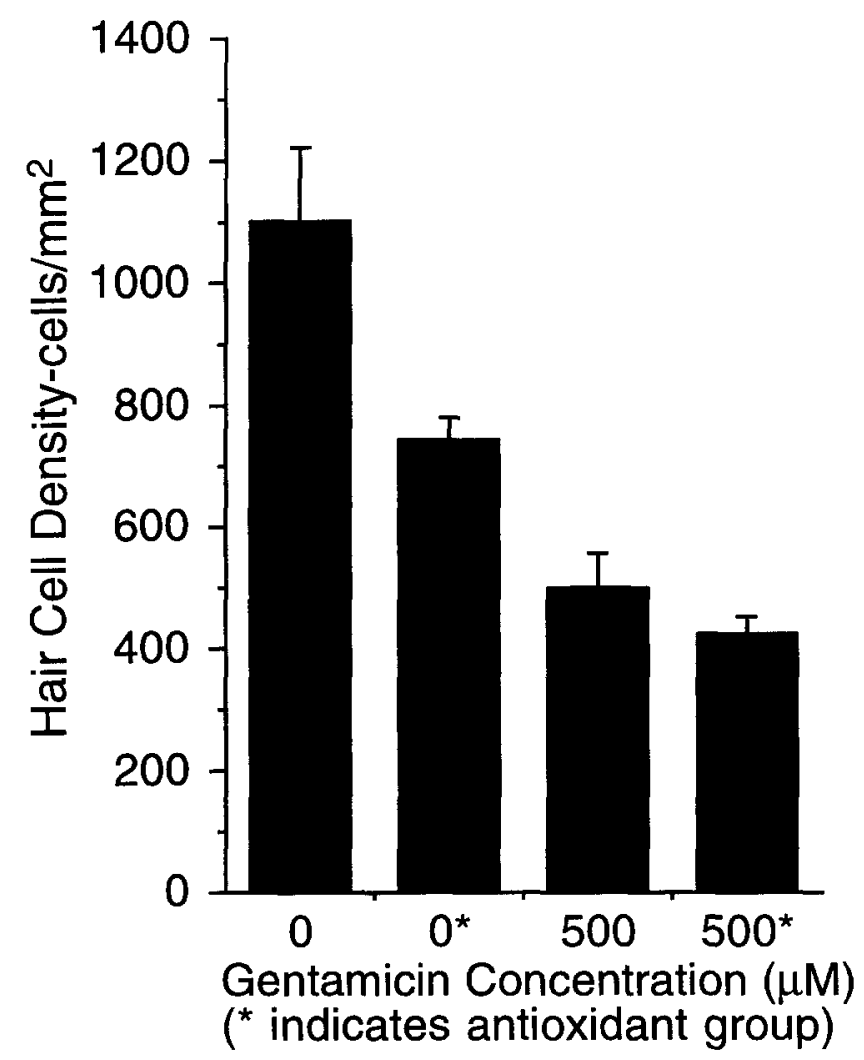

Fig. 9. Hair cell density after exposure to gentamicin and antioxidant. On the left are counts from control cultures and antioxidant exposed cultures; on the right, cultures exposed to $500 \mu \mathrm{M}$ gentamicin for $1 \mathrm{~h}$ and cultures exposed to gentamicin plus antioxidant. The bars with asterisks represent the cultures incubated with antioxidant for $1 \mathrm{~h}$ concomitant with the gentamicin exposure. Hair cell loss due to gentamicin was not attenuated by the presence of antioxidant. In fact, it was worsened in the case of the control, and unaffected within the cultures exposed to $500 \mu \mathrm{M}$ gentamicin. In total, 76 culture wells were analyzed for this experiment. Error bars: SEM.

densities were measured in cultures with the same antioxidants, glutathione and catalase, that demonstrated short-term inhibition of free radical production as measured by suppression of DCFH fluorescence. These cultures were exposed to $500 \mu \mathrm{M}$ gentamicin with an antioxidant or to an antioxidant alone for $1 \mathrm{~h}$, washed, allowed to survive in normal culture media for $6 \mathrm{~h}$, and then fixed and stained to assess degree of hair cell loss. A total of 76 cultures were used for this experiment. While the antioxidants were effective in suppressing the short latency burst of free radical production, the hair cells continued to succumb to the effects of gentamicin despite supplementation with glutathione or catalase. The decrease in hair cell density observed with $500 \mu \mathrm{M}$ gentamicin was unchanged with the addition of antioxidant. Fig. 8 shows representative fluorescent photo-micrographs of cultures stained with rhodamine-phalloidin from this experiment. Fig. 8A shows a control explant with fairly regular stereocilia bundles and a tightly packed array of hair cells. Hair cell den- sity in this explant is 1101 cells $/ \mathrm{mm}^{2}$. Fig. $8 \mathrm{~B}$ is an explant exposed to $10 \mu \mathrm{M}$ glutathione alone. Notice the significant decrease in the number of stereocilia bundles and the slightly expanded apical surfaces of these hair cells. Hair cell density in this culture was 744 cells $/ \mathrm{mm}^{2}$. Fig. $8 \mathrm{C}$ is an explant after exposure to $500 \mu \mathrm{M}$ gentamicin (density $=500$ cells $/ \mathrm{mm}^{2}$ ) and Fig. $8 \mathrm{D}$ is an explant after exposure to $1000 \mu \mathrm{M}$ gentamicin (density $=269$ cells $/ \mathrm{mm}^{2}$ ). In the latter two panels, it is clear that the normal morphology of the hair cell is disrupted, stereocilia bundles are nearly absent, and the apical surfaces of the few remaining hair cells are 3-4 times normal size.

Mean hair cell densities from the groups exposed to gentamicin, antioxidant, or both are presented in Fig. 9. The graph demonstrates the rather large difference between hair cell density in the control group versus the group that was treated with antioxidant alone. Contrary to expectations, it appeared that treatment with antioxidant alone had deleterious effects on hair cells. The second two bars demonstrate hair cell density in cultures exposed to $500 \mu \mathrm{M}$ gentamicin alone and 500 $\mu \mathrm{M}$ gentamicin with antioxidant. Here the difference between the two groups is minimal.

Analysis of the different treatment groups with multiple comparisons confirmed that neither catalase nor glutathione significantly altered the decrease in hair cells density caused by gentamicin exposure. Further analysis, after grouping the cultures treated with antioxidants, revealed a small but significant decrease in hair cell density due to the effects of the antioxidants alone $(P=0.01)$. As for the gentamicin-treated groups, there was no significant difference between those cultures treated with gentamicin and those treated with gentamicin and antioxidant $(P=0.4)$.

Under these conditions, free radical scavengers did not appear to have a protective effect against gentamicin ototoxicity on chick basilar papilla in vitro. Based on these findings, we directed our attention toward evaluating the efficacy of catalase and glutathione during a long-term incubation. We had shown that these antioxidants were both effective in attenuating free radical production over a $3 \mathrm{~min}$ period, based on their ability to suppress the increase seen in DCFH fluorescence after short-term gentamicin exposure. However, in the cell density experiments, we were exposing hair cells to gentamicin for $1 \mathrm{~h}$ and anticipating that the antioxidant that we used in conjunction with gentamicin would be effective for the entire period. Therefore, to assess the free radical scavenging activity of catalase and glutathione, we pretreated hair cells in culture with catalase or glutathione for $1 \mathrm{~h}$, and then performed the DCFH imaging experiment. Results showed that neither catalase nor glutathione were able to suppress the production of free radical production after a $1 \mathrm{~h}$ incubation at $37^{\circ} \mathrm{C}$ (data not shown). 
We concluded, therefore, that neither catalase nor glutathione was continuously effective in suppressing the production of free radicals after $1 \mathrm{~h}$ incubation at $37^{\circ} \mathrm{C}$. Because these reagents did not appear to maintain their antioxidant properties throughout the entire incubation period with gentamicin, we cannot confirm or deny the protective role of antioxidants in aminoglycoside-induced hair cell death. Furthermore, it was found that antioxidants alone may have a deleterious effect in these hair cell cultures at these concentrations.

\section{Discussion}

Production of oxygen free radicals has been examined in many different organ systems, and it has been implicated as an important event in the cascade of cellular changes culminating in cell death in many pathological and developmental processes (Siesjo et al., 1989; Korsmeyer et al., 1993; Dugan and Choi, 1994). The role of free radicals in ototoxic hair cell death has been secondarily implicated by studies demonstrating a protective effect of antioxidants (Pierson and Møller, 1981; Hoffman et al., 1987; Garetz et al., 1994). However, previous studies have not directly demonstrated that hair cells produce a rise in free radicals in response to aminoglycoside exposure. In the present experiments, we have demonstrated that hair cells rapidly produce free radicals when exposed to gentamicin and do so in a dose-dependent fashion. While there is a significant difference between the in vivo setting of chronic, low-dose aminoglycoside exposure and the in vitro setting of acute, high-dose drug exposure, it is possible that this production of free radicals is relevant in the in vivo setting. Furthermore, the assay for free radical production that was used, DCFH, is used to detect hydrogen peroxide. It is possible that another free radical is produced in addition to peroxide, that is not suppressed by either catalase or glutathione, and therefore a potential beneficial effect of antioxidants went undetected.

Hair cell damage due to gentamicin exposure in vivo has been shown to have a specific predisposition for the high frequency, or basal, end of the cochlea in both birds and mammals. However, in some in vitro studies, this predilection for hair cell loss in the basal cells is not maintained (Richardson and Russell, 1991). We sought an explanation for this susceptibility by separating cultures containing basal hair cells from those containing apical hair cells. In these experiments, we were unable to detect a difference in free radical production between these two hair cell populations. Nor did decreasing the concentration of gentamicin from 1000 to $100 \mu \mathrm{M}$ unveil any differences between the two hair cell populations. Therefore, it appears unlikely that the sensitivity of the basal hair cells to gentamicin in vivo is caused by a greater degree of free radical activity in this cell type.
We also evaluated density of hair cells in these cultures after exposure to different concentrations of gentamicin. Hair cell death occurred in a dose-dependent fashion when cultured chick papillae were exposed to gentamicin. It is important to note, however, that this dose-dependent susceptibility to aminoglycoside was demonstrated only in the apical hair cell population. We were unable to demonstrate a dose-dependent hair cell loss in the basal population, largely because most of the basal hair cells were dying in all treatment groups, including the control group, as compared to the apical hair cell group.

It appears that basal hair cell survival in culture is compromised within hours after removal of the basilar papilla (Stone and Rubel, personal communication). In our imaging studies which were conducted after $48 \mathrm{~h}$ in culture, it was clear that the basal hair cells were less densely populated than the apical hair cells. Yet, in those explants that did bear viable basal hair cells, there was no detectable difference in free radical production in the basal as compared to the apical hair cells in either controls or drug treated explants. We have begun to examine factors that may be necessary to support these basal hair cells in culture with hopes that if we can address the issues that render these hair cells vulnerable in vitro, we may be able to understand what makes avian basal hair cells, and perhaps mammalian basal hair cells, differentially susceptible to many different ototoxic stimuli in vivo, including aminoglycosides (Cruz et al., 1987; Tucci and Rubel, 1990; Duckert and Rubel, 1990; Girod et al., 1991).

In the next experiment, we counted hair cell density after exposure to gentamicin and antioxidants. This experiment was designed to assess whether the production of free radicals was necessary to cause hair cell loss. We have demonstrated that both catalase and glutathione successfully block the production of free radicals during the first few minutes of gentamicin exposure. However, we also found that the antioxidants, glutathione and catalase did not exert any protective effect against hair cell loss when the cells were exposed to gentamicin for $1 \mathrm{~h}$. However, upon further examination, it appears that antioxidant activity was not sustained throughout the entire $1 \mathrm{~h}$ incubation period with gentamicin. Therefore, we were unable to adequately test whether inhibiting free radical production is an effective way to protect hair cells from aminoglycoside toxicity in this culture preparation.

\subsection{Reactive oxygen species in hair cells}

The most important contribution of the experiments presented here is a direct demonstration of a dose dependent increase in free radicals in hair cells exposed to gentamicin. Schacht (1986) have postulated that inhibition of the phosphatidyl inositol signal transduction 
pathway may be one way in which gentamicin exerts its effect on hair cells. Our data show that the acute response of hair cells to gentamicin is so rapid that free radicals may be produced by direct interaction of gentamicin with the plasma membrane, or by some very early steps of the PIP signal transduction pathway. The possible sources of this rapid burst of free radicals include reactions that occur at the level of the plasma membrane, such as NADPH oxidase with subsequent lipid peroxidation (Siesjo et al., 1989). Certain cytoplasmic sources of free radical are feasible in explaining this observation. Such potent enzymes as xanthine oxidase or iron-catalyzed production of superoxide anion are possible contenders (Pierson and Møller, 1982). There is considerable evidence supporting a hair cell protective effect of free radical scavengers in aminoglycoside ototoxicity in vivo (Pierson and Møller, 1981; Hoffman et al., 1987; Garetz et al., 1994a,b). Pierson and Møller (1981) established the inhibition of kanamycin ototoxicity in guinea pigs by a sulfhydryl-containing compound, WR2721. In a later paper, these investigators proceeded to demonstrate the very high specific activity of endogenous superoxide dismutase (SOD) in guinea pig cochlea (Pierson and Møller, 1982). The fact that SOD does have such high levels of activity in the inner ear would suggest that there are conditions, either through an endogenous or exogenous source, that cause superoxide anion to form, necessitating a consistent method of disposing of this toxic compound. While SOD activity has been found to be abundant in the cochlea it may not be sufficiently high to compensate for the amount of free radicals produced by exposure to gentamicin. As noted above, it is also possible that free radicals other than hydrogen peroxide are produced by exposure to gentamicin, and that these are not detected by DCF. If this is the case, then it is very possible that the antioxidants used in our experiments are not the most effective antioxidants in combating gentamicin ototoxicity. The discrepancy between the data presented in our experiments and earlier data supporting a protective role of antioxidants in vivo might be explained in several ways. A major problem with our experiments is that catalase and glutathione do not appear to maintain antioxidant activity throughout the entire incubation period, perhaps because of a limited half-life in culture at $37^{\circ} \mathrm{C}$. Furthermore, there is evidence that glutathione is only somewhat permeable to cells, but a monoester of glutathione is much more permeable (Meister, 1992). It is possible that with improved delivery via an esterified form of glutathione, the hair cells could derive a beneficial effect from this antioxidant. In addition, the reaction which mediates the extensive free radical production within $150 \mathrm{~s}$ after gentamicin exposure might be the initiation of a cascade of reactions, which may be inhibited only in part by catalase or glutathione. Later reactions, if allowed to proceed, may not be inhibited by these particular free radical scavengers. Perhaps another form of antioxidant or a continuous exposure to antioxidant would be more effective at quenching the specific reaction that mediates gentamicin toxicity. The fact remains, however, that both catalase and glutathione were effective in blocking the production of free radicals caused by gentamicin. This suggests that the free radicals are being released from an extracellular source. This finding is compatible with the results seen in the work by Priuska and Schacht (1995), where iron/gentamicin binding, in the absence of cells, caused free radical production.

Finally, since the doses of antioxidant used in our experiments appear to be independently toxic to the hair cells, it may not be possible to assess any potentially beneficial role of antioxidant in gentamicin ototoxicity without a better understanding for how these antioxidants independently react with hair cells. It has been found in a culture cell line that certain thiol-containing compounds at a given concentration can actually have a pro-oxidant effect by means of alternative pathways via metals such as copper to activate hydrogen peroxide (Held and Biaglow, 1994). This seemingly paradoxical effect of thiol compounds might be partially responsible for the deleterious effects of glutathione in hair cells, although we detected no increase in free radicals after the addition of glutathione alone. Also, previous investigators have suggested that the redox state of the cell, represented largely by the $\mathrm{NAD}^{+} /$ NADH ratio, is critical for the survival of the cell (e.g., Larm et al., 1994). It is possible that the antioxidants interfered with the redox state of our hair cells and that the $\mathrm{NAD}^{+} / \mathrm{NADH}$ ratio is altered in such a way that the risk of damage due to free radicals is small, but the depletion of $\mathrm{NAD}^{+}$causes other crucial biochemical pathways, such as glycolysis, to be compromised. There is no evidence based on the data presented here for such an interaction, although this type of reaction could explain what we have observed.

\subsection{Mitochondrial dysfunction and free radical production in aminoglycoside ototoxicity}

A potent source of intracellular free radicals that might play a role in aminoglycoside ototoxicity are the mitochondria. Our experiments did not directly address the possible roles of mitochondria in the production of free radicals. However, clinical epidemiological studies have elucidated a compelling hypothesis of mitochondrial dysfunction as a mechanism or co-factor in aminoglycoside ototoxicity ( $\mathrm{Hu}$ et al., 1991; Jaber et al., 1992; Fischel-Ghodsian et al., 1993; Prezant et al., 1993; Ouweland et al., 1992; Cortopassi and Hutchin, 1994). Several groups have determined that a gene conferring extreme sensitivity to aminoglycoside is carried exclusively via maternal inheritance. This pat- 
tern of inheritance suggests the presence of a mitochondrial mutation which is inherited through maternal transmission of mitochondria. Two different mutations have been isolated in families with profound hearing loss due to aminoglycoside exposure, both of them in mitochondrial DNA. It appears very possible that gentamicin, an antibiotic designed to inhibit bacterial protein synthesis, could inadvertently interfere with mitochondrial protein synthesis given the homology between bacterial and mitochondrial DNA. In the nephrotoxicity literature, gentamicin has been shown to cause enhancement of free radical production in isolated mitochondrial preparations (Shah and Walker, 1992; Yang et al., 1991). While the experiments performed here with cultured hair cells did not demonstrate any role of mitochondria in reactive oxygen production, this does provide a compelling hypothesis.

The abrupt onset of free radical production that we detected suggests a process other than interference with mitochondrial protein synthesis. Aminoglycoside-induced misreading of mitochondrial DNA with subsequent free radical production would probably require hours, not minutes. It is possible, nonetheless, that the free radical production continues much later than the time course studied here, as a result of gentamicin interactions with mitochondrial protein synthesis. We attempted to investigate whether hair cells continued to produce free radicals after $1 \mathrm{~h}$ of drug exposure. Unfortunately, we were unable to achieve sufficient DCFH loading of hair cells after a $30 \mathrm{~min}$ exposure to gentamicin. In this case, the positive control with hydrogen peroxide failed to yield the expected increase in fluorescent intensity. The possibility of continued production of free radicals, therefore, could not be assessed using these methods.

\section{Conclusions}

While the mechanism of aminoglycoside ototoxicity remains elusive, the use of imaging with DCFH and other bioactive indicators may allow investigators to approach this problem from a new perspective. We have established that free radicals are indeed produced by hair cells very rapidly and in a dose-dependent fashion after gentamicin exposure. The question of whether antioxidants have a protective role against gentamicin in our culture setting is still uncertain. It is clear, nonetheless, that there are many more antioxidants that can be applied before abandoning this possibility. In addition, new information generated from clinical studies about mitochondrial mutations and work done in cell cultures with isolated mitochondrial preparations are certain to provide new directions and ideas toward understanding aminoglycoside biochemistry in the inner ear.

\section{Acknowledgments}

We thank Dr. Edward Lachica for his assistance in the development of the DCFH imaging technique, Dr. Jennifer Stone for her instruction on the chick hair cell cultures, Dr. Jialin Shang for her excellent technical assistance, Dr. William Lippe for his help with the statistical analysis, and Dr. Jochen Schacht for his knowledgeable assistance. Supported by NIH Training Grant DC00018, the Deafness Research Foundation, the Oberkotter Foundation and NOHR.

\section{References}

Bock, G., Yates, G., Miller, J. and Moorjani, P. (1983) Effects of Nacetyl-cysteine on kanamycin ototoxicity in the guinea pig. Hear. Res. 9, 255-262.

Cortopassi, G. and Hutchin, T. (1994) A molecular and cellular hypothesis for aminoglycoside-induced deafness. Hear. Res. 78, 2730.

Cruz, R.M., Lambert, P.R. and Rubel, E.W (1987) Light microscopic evidence of hair cell regeneration after gentamicin toxicity in chick cochlea. Arch. Otolaryngol. Head Neck Surg. 113, 1058-1062.

Duckert, L. and Rubel, E.W (1990) Ultrastructural observations on regenerating hair cells in the chick basilar papilla. Hear. Res. 48 , $161-182$

Dugan, L.L. and Choi, D.W. (1994) Excitotoxicity, free radicals, and cell membrane changes. Ann. Neurol. 35, 817-821.

Fischel-Ghodsian, N., Prezant, T. Bu, X. and Oztas, S. (1993) Mitochondrial ribosomal RNA gene mutation in a patient with sporadic aminoglycoside ototoxicity. Am. J. Otolaryngol. 14, 399-403.

Garetz, S., Altschuler, R.A. and Schacht, J. (1994a) Attenuation of gentamicin ototoxicity by glutathione in guinea pig in vivo. Hear. Res. 77, 81-87.

Garetz, S., Rhee, D. and Schacht, J. (1994b) Sulfhydryl compounds and antioxidants inhibit cytotoxicity to outer hair cells of a gentamicin metabolite in vitro. Hear. Res. 77, 75-80.

Girod, D.A., Tucci, D.L. and Rubel, E.W (1991) Anatomical correlates of the functional recovery in avian inner ear following aminoglycoside ototoxicity. Laryngoscope 101, 1139-1149.

Heck, D.E., Laskin, D.L., Gardner, C.R. and Laskin, J.D. (1992) Epidermal growth factor suppresses nitric oxide in the regulation of wound healing. J. Biol. Chem. 267, 21277-21280.

Held, K.D. and Biaglow, J.E. (1994) Mechanisms for the oxygen radical-mediated toxicity of various thiol-containing compounds in cultured mammalian cells. Radiation Res. 139, 15-23.

Henley, C.M. and Rybak, L.P. (1993) Developmental ototoxicity. Otolaryngol. Clin. N.Am. 20, 857-871.

Hoffman, D., Jones-King, K.L., Whitworth, C. and Rybak, L. (1988) Potentiation of ototoxicity by glutathione depletion. Ann. Otol. Rhinol. Layrngol. 97, 36-41.

Hoffman, D., Whitworth, C., Jones, K. and Rybak, L. (1987) Nutritional status, glutathione levels, and ototoxicity of loop diuretics and aminoglycoside antibiotics. Hear. Res. 31, 217-222.

Hu, K.-N., Qui, W.-Q., Su, B.-T., Fang, L.-A., Zhou, F., Gu, Y.-P., Zhang, Q.H., Yan, J.-H., Ding, Y.-Q. and Wong, H. (1991) Genetic aspects of antibiotic-induced deafness: mitochondrial inheritance. J. Med. Genet. 28, 79-83.

Hutchin, T. and Cortopassi, G. (1994) Proposed molecular and cellular mechanism for aminoglycoside ototoxicity. Antimicrob. Agents Chemo. 38, 2517-2520.

Jaber, L., Shohat, M., Bu, X., Fischel-Ghodsian, N., Yang, H.-Y., Wang, S. and Rotter, J. (1992) Sensorineural deafness inherited as 
a tissue specific mitochondrial disorder, J. Med. Genetic. 29,8690.

Korsmeyer, S.J., Shutter, J.R., Veis, D.J., Merry, D.E. and Oltvai, Z.N. (1993) Bcl-2/Bax: a rheostat that regulates an antioxidant pathway and cell death. Sem. Cancer Bio. 4, 327-332.

Kotecha, B. and Richardson, G.P. (1994) Ototoxicity in vitro: effects of neomycin, gentamicin and dihydrostreptomycin, amikacin spectinomycin, neamine, spermine, and poly-t-lysine. Hear. Res. 73, $173-184$.

Larm, J.A., Vaillant, F., Linnane, A.W. and Lawen, A. (1994) Upregulation of the plasma membrane oxidoreductase as a prerequisite for the viability of human Namalwa $\rho^{\circ}$ cells. J. Bio. Chem. 269, 30097-30100

Matz, G.J. (1993) Aminoglycoside cochlear ototoxicity. Otolaryngol. Clin. North Am, 26, 705-712.

Meister, A. (1992) On the antioxidant effects of ascorbic acid and glutathione. Biochem. Pharm. 44, 1905-1915.

Nasr-Esfahahi, M.H., Aitken, J.R. and Johnson, M.H. (1990) Hydrogen peroxide levels in mouse oocytes and early cleavage stage embryos developed in vitro or in vivo. Development 109, 501 . 507.

Oesterle, E.C., Tsue, T.T., Reh, T.A. and Rubel, E.W (1993) Hair cell regeneration in organ cultures of the postnatal chicken inner ear. Hear. Res. 70, 85-108.

Ouweland, J., Lemkes, H., Ruitenbeck, W., Sandkuijl, L., Vijider, M., Struyvenberg, P., van de Kamp, J. and Maasen, J. (1992) Mutation in mitochondrial tRNA Leu(UUR) gene in a large pedigree with maternally transmitted type II diabetes mellitus. Nature Genet. $1,368-371$.

Pierson, M.G. and Møller, A.R. (1981) Prophylaxis of kanamycininduced ototoxicity by a radioprotectant. Hear Res. 4, 79-87.

Pierson, M.G. and Møller, A.R. (1982) Superoxide dismutase activity in the cochlea. Hear. Res. 6, 141-151.

Prezant, T.R., Agapian, F.V., Bohlman, M.C., Bu, X., Sitki, O., Qiu, W.Q., Arnos, K.S., Cortopassi, G.A., Jaber, L, Rotter, J., Shohat, $M$. and Fischel-Ghodsian, N. (1993) Mitochondrial ribosomal RNA mutation associated with both antibiotic-induced and nonsyndromic deafness. Nature Genet. 4, 289-294.

Priuska, E.M. and Schacht, J. (1995) Formation of free radicals by gentamicin and iron and evidence for an iron/gentamicin complex. Biochem. Pharmacol. 50, 1749-1752.
Reynolds, I.J. and Hastings, T.G. (1995) Glutamate induces the production of reactive oxygen species in cultured forebrain neurons following NMDA receptor activation. J. Neurosci. 15, 3318-3327.

Richardson, G.P. and Russell, I.J. (1991) Cochlear cultures as a model system for studying aminoglycoside induced ototoxicity. Hear. Res. 53, 293-311.

Saito, H., Jukumura, D., Kurose, I., Suematsu, M., Tada, S., Kagawa, T., Miura, S., Morizane, T. and Tsuchiya, M. (1992) Visualization of oxidative processes at the cellular level during neutrophil-mediated cytotoxicity against a human hepatoma cell line, HCC-M. Int. J. Cancer. 51, 124-129.

Schacht, J. (1986) Molecular mechanisms of drug induced-hearing loss. Hear. Res. 22, 297-304.

Schacht, J. (1993) Biochemical basis of aminoglycoside ototoxicity. Otolaryngol. Clinics N.Am. 26, 845-856.

Shah, S.V. and Walker, P.D. (1992) Reactive oxygen metabolites in toxic acute renal failure. Ren. Fail. 14, 363-370.

Siesjo, B.K., Agard, C.-D. and Bengtsson, F. (1989) Free radicals and brain damage. Cerebrovasc. Brain Metab. Rev. 1, 165-211

Stone, J.S., Kelley, M. and Rubel E.W (1995) Supporting cell proliferation and hair cell differentiation in aminoglycoside-treated explants of the mature chick cochlear epithelium. Assoc. Res. Otolaryngol. Abstract 18, 83.

Stone, J.S., Leano, S.G., Baker, L.P. and Rubel, E.W (1996) Hair cell differentiation in the chick cochlear epithelium following aminoglycoside toxicity: In vivo and in vitro observations. J. Neurosci. $19,6157-6174$.

Suzuki, H., Suematsu, M., Miura, S., Asako, H., Kurose, I., Ishii, S., Houzawa, S. and Tsuchiya, M. (1993) Xanthine oxidase-mediated intracellular oxidative stress in response to cerulein in rat pancreatic acinar cells. Pancreas 8, 465-470.

Swann, J. and Acosta, D. (1990) Failure of gentamicin to elevate cellular malondialdehyde content or increase generation of intracellular reactive oxygen species in primary cultures of renal cortical cells. Biochem. Pharm. 40, 1523-1526.

Tucci, D.L. and Rubel E.W (1990) Physiologic status of regenerated hair cells in the avian inner ear following aminoglycoside ototoxicity. Otolaryngol. Head Neck Surg. 103, 443-450.

Yang, C.L. Du, X.H. Zou, W.Z. and Chen, W. (1991) Protective effect of zinc-induced metallothionein synthesis on gentamicin nephrotoxicity in rats. Ren. Fail. 13, 227-232. 